\title{
Developing the Greek Reference Index for the Social Sciences and Humanities
}

\author{
Victoria TSOUKALA, a,1 Alexia PANAGOPOULOU ${ }^{\text {a }}$, Giorgos STAVROU ${ }^{\text {a }}$, Eleni \\ ANGELIDI ${ }^{\text {a }}$, Evi SACHINI ${ }^{\text {a }}$, Alexandros NAFPLIOTIS ${ }^{\text {a }}$ \\ ${ }^{a}$ National Documentation Centre/National Hellenic Research Foundation, Athens \\ Greece
}

\begin{abstract}
The Greek Reference Index for the Social Sciences and Humanities (GRISSH) is a service that collects, documents, stores and, where possible, provides access to peer-reviewed publications in the Social Sciences and the Humanities (SSH) by Greek publishers. It also provides long-term preservation for the digital and print files of the publications. The GRISSH was conceived by the National Documentation Centre (EKT) and the documentation and access platform is developed by the organization itself (OpenABEKT). The GRISSH is, in essence, a collaborative project that advances with the assistance and active participation of the publishing and scholarly community in Greece. It is intended as an essential reference service for the research and publishing community in Greece and abroad. The present contribution presents the goals, objectives and key benefits of the project; the evaluation criteria for the selection of content; the specifications for the development of the index; the methodology of documentation; the emerging collaborations with stakeholders. It also, present how the GRISSH project is aligned with the national and international agendas in view of a coordinated development and e-infrastructure that will support the sectors of academia, research and academic publishing.
\end{abstract}

Keywords. Greek Reference Index, Social Sciences and Humanities, peer review content, open access, documentation, services, e-infrastructures

\section{Introduction}

The National Documentation Centre $(E K T)^{1}$ is the national institution for the aggregation, documentation and dissemination of scientific information. Founded in 1980, the organization serves the country's research, education and business communities and the wider public. At EKT, scientific content e-infrastructures embrace technological innovation in fulfilling its main mission to aggregate, document, store and preserve digital content and disseminate it openly to the public in a way that promotes growth, research and innovation. Placing emphasis on multi-directional content reuse, EKT develops enabling factors for the creation, use and growth of digital content in its entire lifecycle.

Access to knowledge lies at the heart of EKT's activities. The organization is a strong supporter of open access as a means for social and economic development. It stands at the forefront of national and international open access initiatives at the policy

${ }^{1}$ Victoria Tsoukala, National Documentation Centre/ National Hellenic Research Foundation, Leoforos Vassileos Konstantinou 48, Athens 16635, Greece. Email: tsoukala@ekt.gr 
and infrastructure level, such that allow the optimal circulation of scientific knowledge and digital culture for the benefit of society and economy.

In this context EKT develops e-infrastructures for scientific and cultural information with integrated value-added services of national and international impact. Such services of EKT's e-infrastructures are, for example, the National Archive of PhD Theses (www.phdtheses.ekt.gr), the ePublishing services (http://epublishing.ekt.gr), and repository services (Software as a Service). EKT's e-infrastructure development is co-financed by Greece and the European Union/European Regional Development Fund (Operational Program "Digital Convergence") through a large-scale project, the National Information System for Research and Technology (NISRT) (www.epset.gr).

This paper presents a new and innovative project in EKT's Humanities new agenda, the Greek Reference Index of Scholarly Publications in the Social Sciences and Humanities (henceforth GRISSH). The paper focuses on explaining the aims, scope and context behind this new project, the methodology used in implementing the project, the future planning and expected impact.

\section{The GRISSH and its context: aims, scope and relevance}

The GRISSH is a service that collects, documents, stores and, where possible, provides access to peer-reviewed publications in the Social Sciences and the Humanities (SSH) by Greek publishers. At the same time, it will provide long-term preservation for the digital and print files of the publications. The GRISSH was conceived by EKT and the documentation and access platform is developed by the organization itself. The GRISSH is a collaborative project that advances with the assistance and active participation of the publishing and scholarly community in Greece, whose needs it primarily addresses. The GRISSH is envisioned as part of a wider index that will gradually record the high quality publications of the country in all fields. At EKT we envision the GRISSH as becoming an essential reference service (hence the name Reference Index) for the research and publishing community, primarily in Greece but also abroad.

The project is currently close to launching the platform in a beta form that will be open for evaluation and comments by the stakeholder community in the early summer 2014. The platform will contain a sample of the material to start with.

With the GRISSH we aim to:

- Index and record in detail the Greek output in publications in the Social Sciences and the Humanities and provide access to it from a single point in the web

- Provide an essential research tool for the Greek and international research community in the SSH with enhanced search and browsing capabilities of the indexed content at the article level

- Promote the Greek scientific output as well as the research produced in the Greek language internationally and contribute to its increased international relevance

- Contribute to the long-term preservation of the aggregated content

- Afford the extraction of metrics and indicators regarding the Greek peerreviewed output in the $\mathrm{SSH}$, in such ways that they can serve evidence-based policies, and inform decisions of researchers, research performing and research funding institutions. 
- Provide to Greek publishers indexing, repository and content management services for published work, as well as metrics regarding their use and impact

- Contribute to the development of a tight network of collaborating research and publishing institutions in the country in the SSH whom the GRISSH serves and through whom it is made possible

- Be part of a wider international network for similar indexes developed by European Member States and other countries in the SSH and other fields and interoperate with them.

EKT has, since many years, identified the fields of the Humanities and the Social Sciences as ones of great potential with regard to developing e-infrastructures and has, accordingly, directed numerous of its activities there, ${ }^{2}$ which now also include the innovative pilot project GRISSH. This project addresses primarily the lack of systematic indexing of the Greek output in the SSH and the lack of international visibility, especially for the publications in the Greek language. Further, it essentially offers the structured information on which metrics and other indicator systems can be developed for the SSH publications in the future. The lack of indexing, and thus visibility, can be attributed to the particular research processes in the $\mathrm{SSH}$, whereby the research and publication process is a much longer, and often a solitary, process, whose outputs in publications may take years to materialize. The SSH thus display a much slower dissemination process than, for example, the natural or medical sciences, and one that until recently has relied a lot less on technology than the first. Regional studies in the Social Sciences and the Humanities, often carried out in the local languages, in this case in Greek, further act as a factor of 'isolation', in the sense that this type of research is very difficult to include in international indices, such as the ISI or Scopus and disseminate widely. Finally, in contrast with other scientific output, Social Sciences and Humanities research is harder to evaluate using the standard methodology of referencing and impact factors ${ }^{3}$. For all of these reasons, EKT considers that recording the Greek publications in the SSH and making them widely available is of prime importance and urgency.

These issues have long since been identified and have prompted relevant efforts in Europe, turning the attention to the significance of national infrastructures that document and promote the dissemination of digital content in the Social Sciences and Humanities. Countries with strong presence in regional studies and languages other than English are engaged in producing similar indexes that record their output. In Norway, the Norwegian Association of Higher Education Institutions set up a national research database in 2004 containing the bibliographical details of all significant academic publications in all fields of science and scholarship, i.e. including the humanities. Also, in Flanders in 2009 work began to construct the Flemish Academic Bibliographic Database for Social Sciences and Humanities (VABB-SHW) ${ }^{4}$. Additionally, the European Science Foundation (ESF) started the initiative for the European Reference Index for the Humanities (ERIH) ${ }^{5}$, aimed at presenting the Humanities's impressive track record and ongoing research achievements systematically to the rest of the world. It is within this context that the GRISSH is being developed; further, it has been considered of vital strategic importance that our effort align with such national and international agendas as described above in view of a coordinated development and e-infrastructure that will support the sectors of academia, research and academic publishing.

The GRISSH will offer some core benefits to the Greek research, academic and publishing community: a powerful single gateway to a bibliographic database of Greek 
publications in the Social Sciences and Humanities, international exposure and greater visibility for the publications, and the ability to reuse open access content. It will facilitate statistical and evaluative information-gathering as there is provision for a systematic metrics service that will document the impact and use of this content. It will afford easier communication of this national database with those of other European countries and with the European database that has been envisioned by the ESF. Finally, a by-product of this endeavor will be a wider re-use framework of this content for business innovation, education and lifelong learning.

\section{Implementing the Index: Methodology and status of work}

\subsection{Content selection}

Recognizing that the selection of content is of critical significance for the GRISSH, EKT developed an acquisition policy in order to compile an initial list for its content. The first content target group, on account of its scholarly significance, has been the SSH journals published in Greece. Other types of materials will be included in the future, such as monographs. Aim of the acquisition policy was to initially identify the most important journals in the SSH produced in Greece. In doing so, it is understood that this initial list may change many times in the future, as GRISSH will depend on the characteristics of the publications themselves. The policy was broadly based on a number of quality criteria set by indexing services, such as the European Reference Index for the Humanities or Jstor, as well as criteria determined by the aim to reflect as accurately as possible the quality-assured journals of the country in the $\mathrm{SSH}$ in the Reference Index6. Those criteria are: that the journals implement specific evaluation/quality assurance processes for their publications; that they are 'active' journals and display timeliness of publication; that they may have very recently ceased to operate but have displayed timeliness and quality assurance for long periods in the past and are considered significant tools for research by their respective research communities; that their subject-matter is not strictly focused on a specific location in Greece (e.g. local city journals); that they are the official instruments of publication of the research of the important Greek universities and research centers. The starting point was a list of scientific periodicals published in Greece that was included in European Reference Index for Humanities in 2007. These periodicals were hailed as important in their respective area of expertise, by consortiums of science experts. Additionally, a thorough search in Ulrich's index, afforded an initial list of approximately 165 journals that had to be examined. With the help of experts in the various fields and using the aforementioned criteria approximately 85 journals were validated for inclusion in the GRISSH, an estimated total of about 40.000 articles to be documented in the bibliographic database.

Subsequently, a strategy was developed to involve the publishers in the project and spearhead the collection of publications. In communicating with the publishers due attention was paid to conveying to them the significance of the venture and the benefits for them, as well as being consistent with written and phone communication. As a result of a successful communication campaign, publishers have been motivated and have submitted their journals in print form to EKT. The organization now possesses most of the journals comprising the list in actual print copies. As part of our digitization and long-term preservation strategy, digitization will take place where necessary. 


\subsection{Technology}

The specifications for the development of the Index are laid on two tiers: developing the bibliographic e-infrastructure that will be used for the documentation and developing the user interface for the end user.

The bibliographic system that supports the GRISSH is the OpenABEKT, an online tool developed by EKT. Developing the functionalities that will serve the purposes of the GRISSH was a very important stage in proceeding with the project. The OpenABEKT web platform serves for the documentation of periodicals, issues and articles using UNIMARC as the metadata schema of the system. Each record entry into the system is essentially part of the Index database. The core benefits of the web platform are: (a) it provides different documentation forms to cater for the documentation needs of both experienced (i.e. librarians) and non-experienced end users (i.e. publishers); (b) it is easy to access to, navigate and search in the content; Given that one of the key goals of the Index is to provide, in the future, to participating publishers the ability to insert metadata by themselves, care was giving in developing a user-friendly interface for non-specialized users that comprises forms with free text, drop down menus and controlled value lists facilities. The OpenABEKT has the following functionalities for the end users: view the journals, issues and articles lists; submit new items; edit past submissions; create authorities using simple, user-friendly forms; upload the digital copies of the articles as well as publication covers.

For designing the web interface and functionalities of the Index a Best Practices 7 research was implemented so that widely-used functionalities are adopted. The specifications for the development of the index platform were designed to cater for usability, content accessibility and satisfaction by delivering two-tiered user services: experienced and non-experienced user. The platform functionalities are: simple and advanced search, browsing by Author, Subject, Frascati subject category, periodical and publisher, search filters for defining results, refinement of the search results, keyword search through open-access digital files and statistical information on the use, content and Index users. Moreover, users will be able to view the full bibliographic metadata records and the article references, to view and save open access digital files of their choice, to export citations of an article in various bibliographic styles, such as Harvard and APA, and to print, send by email and share items with their social networks.

\subsection{Documentation}

For the documentation of the journals and articles it was necessary to collect all controlled vocabularies, thesauri and authority names and subjects in order to create a core database of authority files for the Social Sciences and Humanities.

Considering that thematic documentation of articles is of major importance, as it facilitates information retrieval from the Index, we designed and created a workflow for developing a controlled vocabulary of authority subject headings. Developing a thorough inventory of the fields within the Social Sciences and Humanities, we researched and compiled subject headings from the Library of Congress online catalogue. The chosen main subject headings were 31 records. These records include 
coded information about wider and narrower relationships with other subjects. By using OCLC service tool we downloaded the 31 records and mapped them from Marc21 to UNIMARC. Finally we entered them into the database and linked them to the wider and narrower relationship terms, adding up to a final sum of 2100 subject authority records. The Frascati taxonomy, which also offers a structured thematic map of the Social Sciences and Humanities, was incorporated into our documentation system OpenABEKT in two languages, English and Greek. Thus, by achieving thematic structuring of our content we can draw useful metric information and offer additional search fields and browse functions on the Index platform.

Additionally, we utilized the existing EKT's ePublishing author Index (http://epublishing.ekt.gr) as a basis in compiling the authorities for personal names and publishers that work within the Social Sciences and Humanities. Following that, the authorities were enriched and curated with further elements drawn from the National Library of Greece, the National Book Centre and the Library of the Congress. The English translation of Greek names was performed using the ELOT 743 standard.

Finally, we documented in detail all the 85 journals which were initially selected to be part of the Index, all the issues that EKT received from publishers, along with some articles, in order to test the system and its functionalities in the beta stage.

\section{Future plans}

Having entered a mature phase in the project, whereby the planning, acquisition of content and development of the greatest part of the e-infrastructure is in place, EKT is soon to test the platform and expeditiously document the metadata of all articles in the bibliographic database. The metadata of all journals will be accessible through the platform in the beginning of 2015, along with openly accessible content, where possible.

As underlined above, this is a project whose value will be fully realized when it becomes useful to the scientific community, the publishers, as well as policymakers who are to benefit from it. EKT, therefore, intends to mobilize those stakeholder communities very soon. Their consistent involvement with the GRISSH will help shape its future direction according to the needs of the stakeholder communities it was designed to serve. To ensure that the Index addresses all the current sector thinking, EKT plans to call for consortiums of experts to help with the development and continuing evaluation of the service. In the following months, specialist committees comprising established researchers and academics will be called upon to act as an advisory board. Their role will be to evaluate the development of the Index, to suggest new services based on international best practices, to communicate the needs of the scientific community and to participate in the review process for new content.

The GRISSH in this initial phase is only the basis for the development of the bibliographic database with other types of content, such as monographs and proceedings, for the development of new services, such as statistical and indicator services and citation index services, among others. It is the intention of EKT to eventually incorporate the GRISSH into the central European database for the output in the SSH, once available, so that Greek research outputs are accurately and adequately represented internationally and so that key societal benefits can be harvested through this endeavor. Additionally, EKT intends to instigate close collaboration with other 
countries that have initiated similar efforts for mutual benefit, advancement and alignment of the initiatives. An integrated collaborative policy is being developed towards this aim.

\section{Pictures}
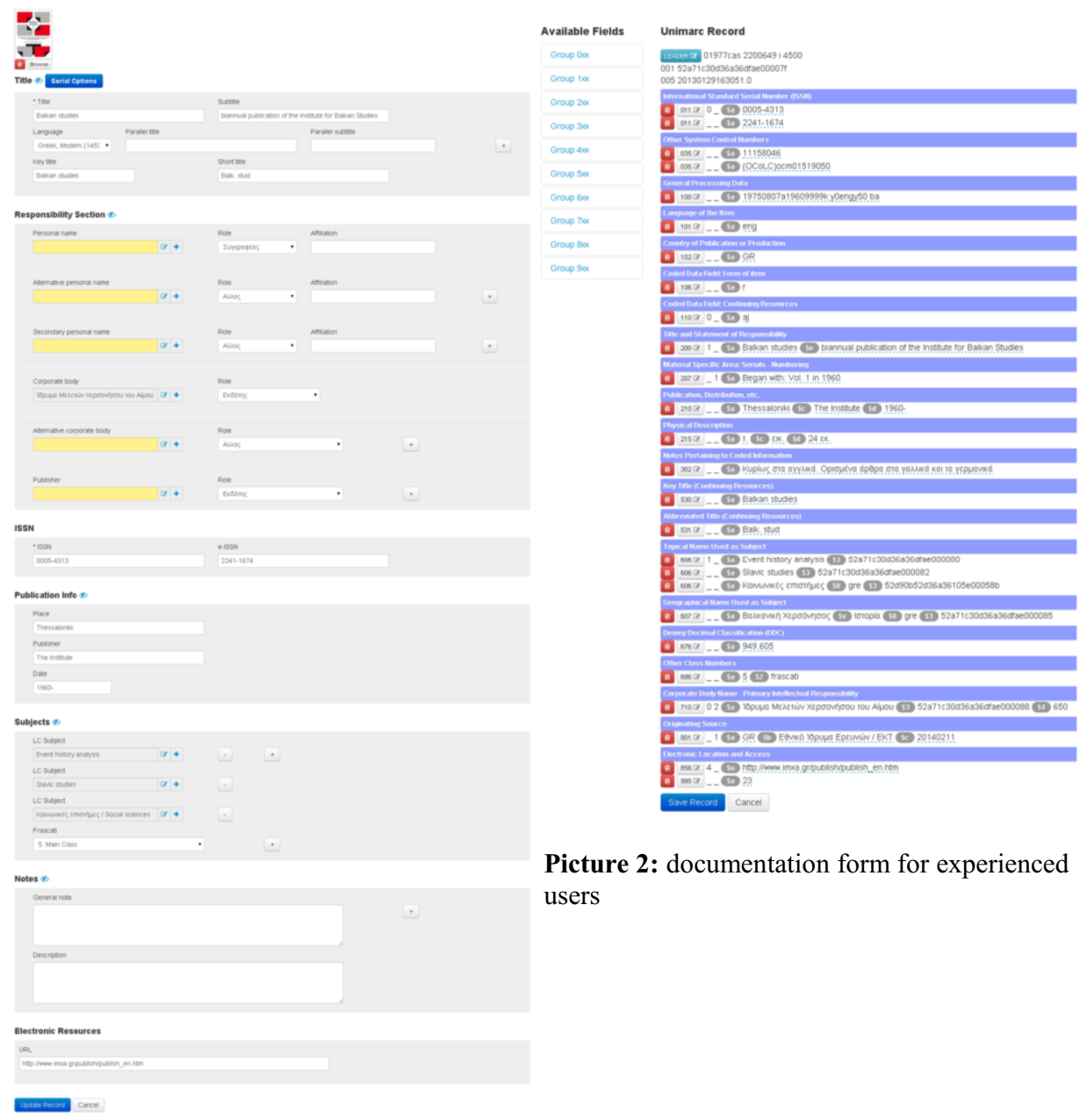

Picture 2: documentation form for experienced users

Picture1: documentation form for nonexperienced users 


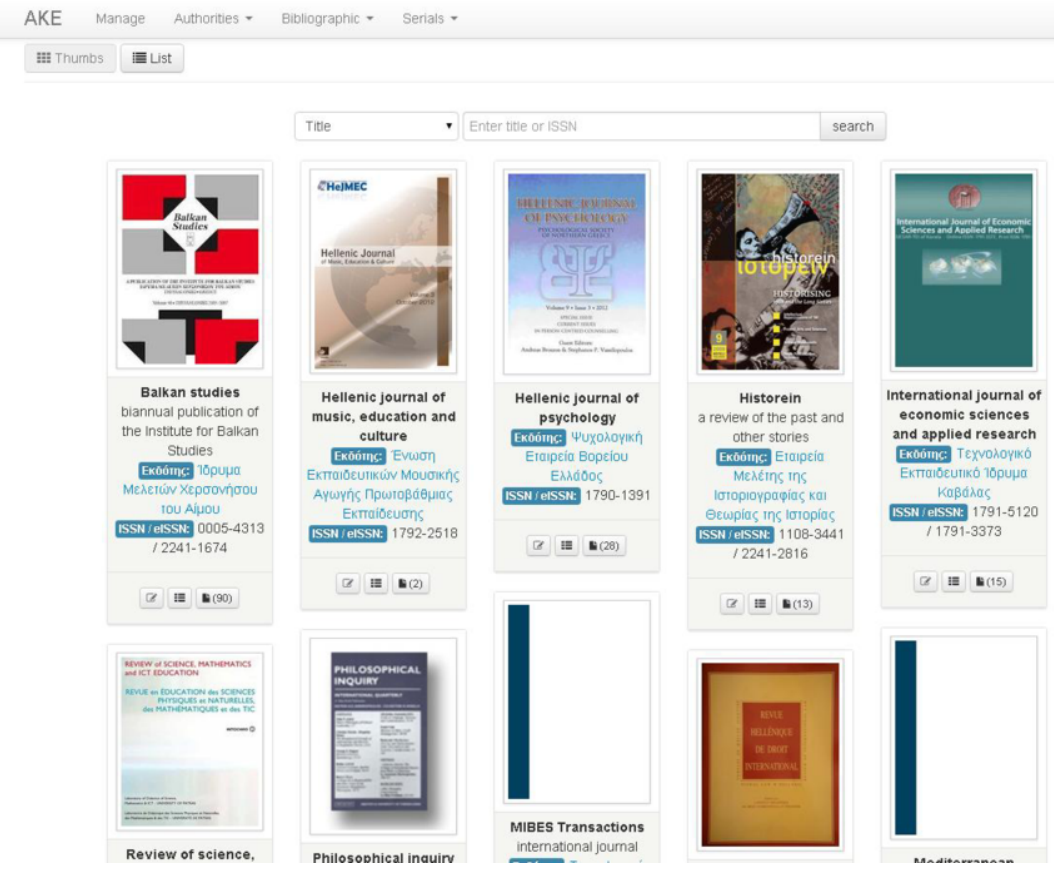

Picture 3: main catalogue at documentation system Open ABEKT

AKE Manage Authorities - Bibliographic - Serials -

Serials / The Historical Review / Vol.10, No.1. (2013)

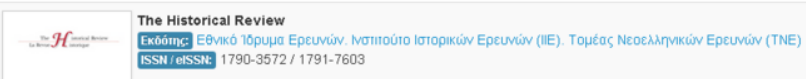

B.

$x$

\begin{tabular}{|c|c|c|c|c|c|}
\hline 1. & I & $\begin{array}{l}\text { Responding to Economic Crises in Historical } \\
\text { Perspective, nineteenth and twentieth centuries }\end{array}$ & $\begin{array}{l}\text { Xaitzniwátwou, Mapia- } \\
\text { Xpioriva, (1955-)/ } \\
\text { Chatzioannou, Maria- } \\
\text { Christina, (1955-) }\end{array}$ & $7-10$ & a) $=8$ \\
\hline 2. & I & $\begin{array}{l}\text { Crises and Merchant Networks in the nineteenth } \\
\text { century : The Case of German Networks in Lombardy }\end{array}$ & Poettinger, Monika & $11-32$ & a $\equiv$ \\
\hline 3. & I & $\begin{array}{l}\text { War, Crisis and Sovereign Loans : The Greek War of } \\
\text { Independence and British Economic Expansion in } \\
\text { the } 1820 \text { s }\end{array}$ & $\begin{array}{l}\text { Xaržniwáwou, Mapio- } \\
\text { Xpiorivo, (1955-)/ } \\
\text { Chatzioannou, Maria- } \\
\text { Christina, (1955-) }\end{array}$ & $33-56$ & (a) $\equiv$ 을 \\
\hline 4. & I & $\begin{array}{l}\text { The Crisis of the Long } 1850 \text { s and Regime Change in } \\
\text { the Ionian State and the Kingdom of Greece }\end{array}$ & $\begin{array}{l}\text { TKékas, Eákns' } \\
\text { Gekas, Sakis }\end{array}$ & $57-84$ & (a) $=$ 으 \\
\hline 5. & I & $\begin{array}{l}\text { L'économie agricole grecque face à la longue crise } \\
\text { de la première globalisation }\end{array}$ & 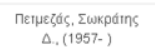 & $85-106$ & a $=6$ \\
\hline 6. & I & $\begin{array}{l}\text { Fighting the Financial Crisis in Greece : The } \\
\text { Privileaed Combanv to Protect Production and Trade }\end{array}$ & Schonnarl Korinna & $107-134$ & a $\equiv$ \\
\hline
\end{tabular}

Picture 4: articles of an issue at documentation system Open ABEKT 


\section{References}

[1] National Documentation Center. Available at: www.ekt.gr

[2] Other important activities are: the repository of primary sources "Pandektis" (http://pandektis.ekt.gr), the repository of the Parthenon frieze (http://repository.parthenonfrieze.gr/frieze/), and the EKT's ePublishing service, which largely focuses on the Social Sciences and the Humanities (http://epublishing.ekt.gr)

[3] Royal Netherlands Academy of Arts and Sciences (2011) "Quality indicators for research in the humanities", Interim report by the Committee on Quality Indicators in the Humanities.

[4] Royal Netherlands Academy of Arts and Sciences (2011) "Quality indicators for research in the humanities", Interim report by the Committee on Quality Indicators in the Humanities.

[5] European Science Foundation, "European Reference Index for the Humanities (ERIH)". Available at: http://www.esf.org/index.php?id=4813

[6] Martin, B., Tang, P., Morgan, M., Glänzel, W., Hornbostel, S., Lauer, G., et al. (2010) "Towards a bibliometric database for the social sciences and humanities-A European scoping project" a report produced for DFG, ESRC, AHRC, NWO, ANR and ESF. Sussex: Science and Technology Policy Research Unit

[7] Ossenblok, T.L.B., Engels, T.C.E., Sivertsen, G. (2012) "The representation of the social sciences and humanities in the Web of Science - A comparison of publication patterns and incentive structures in Flanders and Norway (2005-9)”, Research Evaluation, Vol. 21, Issue 4, pp. 280-290. 